\title{
PREFACE
}

\section{Ekkehard Winterfeldt}

Professor Ekkehard Winterfeldt has been granted (2000, October) as a professor emeritus from the university of Hannover, Germany by his outstanding achievement and contribution not only to the university but also to the country. Well over the period of thirty years, Professor Winterfeldt has been very active and well known in the field of chemistry with respect to his achievements on the synthesis of naturally occurring nitrogen-containing (alkaloids) and thiophene-containing components, particularly on the development of inventive synthetic methodology in his research and achievements with diastereoselective syntheses and the deduction of the structures of natural products.

Professor E. Winterfeldt was born in 1932(May, 13) in Danzig, then Germany and now Poland, and had started to have his chemical training in the universities of Hamburg (1952) and TH Braunschweig before going to Berlin (1956) for his advanced training under the guidance of Prof. F. Bohlmann. In 1956, he completed his chemical study by the work of total synthesis of oenanthetoxin, the poisonous polyene principle of Oenanthe crocata, Umbelliferae, the hemlock water dropwort. And then his research had been successfully advanced to his thesis work of the dissertation on the synthesis of hydroxysparteins which fruitfully completed by 1958 .

In 1959, following the move of his leader Prof. F. Bohlmann, he also moved to the Technical University Berlin where he played active and central role in the research group and was promoted to an assistant professor in Berlin. In 1962, Prof. Winterfeldt obtained his habilitation with the work on the elucidation of the structure and synthesis of naturally occurring thiophene derivatives.

In the following years (1969-), with the work of diastereoselective synthesis of alkaloids, Prof. Winterfeldt was invited to various institutions such as Marburg, Berlin (Technical University), and Hannover over the period of thirty years.

During the course of these years, I (I. N) has been acquainted with him in person not only through exchange of letters but discussions on the works of common interests, thereby being able to publish joint paper on our common alkaloids, particularly on the diastereoselective synthesis and the structure determination of a group of indole alkaloids (isositsirikines).* According to his excellent scientific activity and service, Professor Winterfeldt has been the leader in various societies by chairing their activities including the president of German chemical society. Professor Winterfelt was awarded and decorated with various medals and honors as follows; 
Emil Fischer-Medal (1990) which was awarded for investigations with activated triple bonds and cyclopentanones, as well as the biomimetic synthesis of Camptothecin, Geissoschizin, and Hydrohistorionicotoxin Richard Kuhn-Medal (1995) for stereoselective syntheses of natural products and the development of new synthetic methods and chiral auxiliaries, Adolf Windaus-Medal (1993) for stimulating contributions to the chemistry of steroids and steroidal natural products, Hans Herloff Inhoffen-Medal (1998) for biogenetically oriented syntheses in medicinal chemistry and etc.

By taking advantage of this chance of introducing Professor Ekkehard Winterfeldt, my wife Maya and I are pleased to send our hearty congratulation to Professor Winterfeldt for his outstanding achievements which benefit greatly for the progress of science. Finally we wish my friend has many more good years to come to enjoy life with his family.

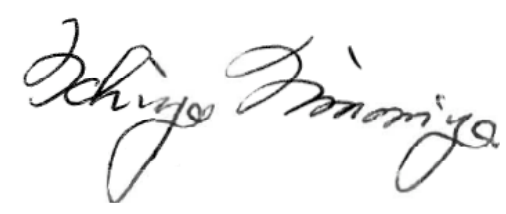

Ichiya Ninomiya

* Synthesis of Corynanthe Alkaloids Corynantheine, Hirsuteine, and the Isositsirikines (by I. Ninomiya, T. Naito, O. Miyata, T. Shinada, E. Winterfeldt, R. Freund, and T. Ishida), Heterocycles, 1990, 30, 1031.

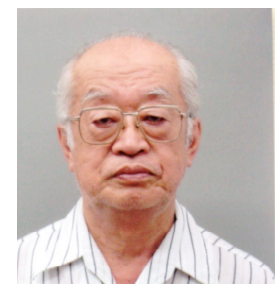

Ichiya Ninomiya, born in Kyoto (1930), graduated from Osaka University, School of Pharmaceutical Sciences, and also graduated from its graduate-school in 1958 and obtained Doctor's.degree on the synthetic work of on Tetracycline (1958). Postdotoral work at the University of California, SanFrancisco (1961-1963), Assistant Professor, Osaka University. Professor, Medicinal Chemistry, Kobe Pharmaceutical University (1968-1996). His research has been focused on the synthetic work of naturally occurring alkaloids, Professor emeritus since 1998. *Professor of organic synthetic research to the graduate students in the H.E.J. Research Institute of Natural Product Chemistry, the University of Karachi, Karachi, Pakistan since 1998. Present status; Professor emeritus, Kobe Pharmaceutical University. and the Professor of Synthetic organic chemistry, H.E.J.Institute of Natural Product Chemistry, University of Karachi, Pakistan. 